www.jmscr.igmpublication.org

Impact Factor 3.79

Index Copernicus Value: 5.88

ISSN (e)-2347-176x ISSN (p) 2455-0450

crossref DOI:_http://dx.doi.org/10.18535/jmscr/v4i1.18

Journal Of Medical Science And Clinical Research

\title{
Stress Hyperglycemia as a Prognostic Indicator in Non-Diabetic ST Elevation Myocardial Infarction Patients
}

\author{
Authors \\ Dr Mohamed Fathy, Prof Yehia Ghanem , Prof Mohamed Sadaka, \\ Prof Azza Abd El-Karim
}

\begin{abstract}
Introduction
Patients either with or without a prior history of diabetes mellitus may present with hyperglycemia during acute myocardial infarction (AMI); it is uncertain whether hyperglycemia upon admission, irrespective of the diagnosis of diabetes, remains an independent predictor of in-hospital morbidity and mortality.

Aim of the study

We aimed in this study to assess the impact of admission blood glucose level on the hospital course and outcome in non diabetic patients presenting with STEMI

Patients and methods

We included 100 non diabetic patients with STEMII divided into two groups: group I included 45 patients with admission blood glucose level less than $180 \mathrm{mg} / \mathrm{dl}$ and group II included 55 patients with admission blood glucose level $180 \mathrm{mg} / \mathrm{dl}$ or more. All patients were subjected to complete history taking and complete clinical examination; 12-lead ECG was performed for every patient and routine laboratory investigations including cardiac enzymes, admission blood glucose level, and HbAlc were estimated at the time of admission of the patients.

Results

There was significant correlation between admission blood glucose level and history of smoking. There was also significant correlation between admission blood glucose level and complications of myocardial infarction including sinus tachycardia, arrhythmia, and ICU length of stay. However, HbAlc level was not found to be correlated with any of the previous parameters.

\section{Conclusion}

We concluded that elevated admission glucose level is a strong predictor of short-term adverse outcome in patients with AMIs. However, the prognostic value of diabetic control (i.e. hemoglobin Alc levels) in patients with AMI is still undefined.
\end{abstract}




\section{INTRODUCTION}

Patients either with or without a prior history of diabetes mellitus may present with hyperglycemia during acute myocardial infarction (AMI). Among patients with no prior history of diabetes, hyperglycemia may reflect previously undiagnosed diabetes, pre-existing carbohydrate intolerance, stressrelated carbohydrate intolerance, or a combination of these ${ }^{(1)}$. Several studies have reported an association between elevated blood glucose upon admission and subsequent increased adverse events, including congestive heart failure (CHF), cardiogenic shock, and death ${ }^{(2,3)}$. However, an overview of these reports ${ }^{(1)}$ was critical of the varying definitions for hyperglycemia (blood sugarranged from $119 \mathrm{mg} / \mathrm{dl}(6.6 \mathrm{mmol} / \mathrm{l})$ to 200 $\mathrm{mg} / \mathrm{dl}(11.1 \mathrm{mmol} / \mathrm{l}))$ and of the sketchy assessment of patient variables, previous medical therapy, and inhospital interventions. Furthermore, many of the studies were conducted in the prethrombolytic era.

Given that the management of diabetes mellitus, other cardiac risk factors, and AMI has evolved significantly since the publication of these reports, it is uncertain whether hyperglycemia upon admission, irrespective of the diagnosis of diabetes, remains an independent predictor of in-hospital morbidity and mortality. The objective of this study was to determine whether the level of blood glucose upon admission remains associated with adverse in-hospital clinical outcomes after AMI in the contemporary era, considering recent advances in treatment, and we sought to take a population-based approach toward examining this question

\section{AIM OF THE STUDY}

We aimed at studying a population of unknown diabetes mellitus with STEMI to evaluate the effect of their admission blood glucose and glycated hemoglobin on their prognosis.

\section{MATERIALS AND METHODS}

\section{Patients}

100 patients with myocardial infarction were included in this randomized clinical trial. Patients were collected from main Alexandria university. The patients included were 83 men and 17 women.

\section{Inclusion criteria}

Adult patient with ST segment elevation myocardial infarction (STEMI) were included.

Patients were diagnosed as having STEMI when they had new or presumed new ST segment elevation of 1 $\mathrm{mm}$ or more seen in any location or new left bundlebranch block with at least one positive cardiac biochemical marker of necrosis (including creatine kinase MB, creatine phosphokinase, or troponin).

\section{Exclusion criteria}

1. Patients with confirmed previous diagnosis of diabetes mellitus,

2. septicemia,

3. endocrine disorders,

4. comorbid conditions (hepatic or renal),

5. Patients on drugs affecting blood glucose levels like glucocorticoids were excluded from study.

6. Patients already taken high glucose diet two hours before admission.

\section{Study Design}

1. Randomized clinical trial.

2. Follow-up evaluation was performed everyday during the study period until patient's discharge and 3 month after discharge.

3. 100 non diabetic patients with STEMI were divided into group I including 45 patients with admission blood glucose level less than $180 \mathrm{mg} / \mathrm{dl}$ and group II including 55 patients with admission blood glucose level $180 \mathrm{mg} / \mathrm{dl}$ or more.

\section{All patients were subjected to the following:}

Complete history taking and complete clinical examination to detect the type of myocardial infarction, hemodynamic instability, and incidence of complications. 


\section{Investigatios}

(1) Serial electrocardiogram.

(2) Echocardiography with its findings about regional wall motion abnormalities and global systolic function.

(3) Serial cardiac enzyme (CK total and CK-MB).

(4) Biochemical tests including kidney function tests, liver function tests, lipid profile, admission blood glucose level, and glycosylated hemoglobin.

Blood samples were taken at the time of admission for $\mathrm{HbA1c}$, blood glucose level on admission, and routine measurements. Samples for FPG level were taken after $8 \mathrm{~h}$ fast. HbA1c was assessed quantitatively using colorimetric technique by glycohemoglobin reagent set.

\section{Statistical analysis and data management}

Data were statistically described in terms of mean $\pm \mathrm{SD}$, median and range, or frequencies (number of cases) and percentages when appropriate. Comparison of numerical variables between the study groups was carried out using the Mann-Whitney $U$-test for independent samples. $P$ values less than 0.05 were considered statistically significant. All statistical calculations were performed using computer program SPSS (statistical package for the social science; SPSS Inc., Chicago, Illinois, USA), version 15 for Microsoft Windows.

$P$ value greater than 0.05 was considered insignificant, $P$ value less than 0.05 was considered significant, and $P$ value less than 0.01 was considered highly significant.

\section{RESULTS}

\section{Comparison between the two studied groups} regarding age

Table (1), show the comparison between the two studied groups regarding age where group one include 45 patient with mean 55.889 \& SD 10.87788. Group two include 55 patient with mean $57.2364 \&$ SD 9.75812. There was no significant difference between the two groups as regard age.

\begin{tabular}{|l|l|l|l|l|l|l|l|}
\hline Age & $\mathbf{N}$ & Min & Max & Mean & S.D & t & $\mathbf{p}$ \\
\hline $\begin{array}{l}\text { RBG } \\
<180\end{array}$ & 45 & 33.00 & 73.00 & 55.8889 & 10.87788 & & \\
\cline { 1 - 5 } $\begin{array}{l}\text { RBG } \\
>180\end{array}$ & 55 & 33.00 & 72.00 & 57.2364 & 9.75812 & .426 & .516 \\
\cline { 1 - 5 } Total & 100 & 33.00 & 73.00 & 56.6300 & 10.24612 & & \\
\hline
\end{tabular}

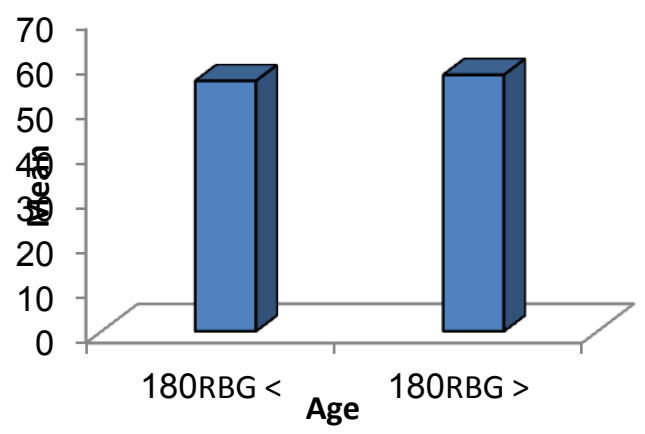

Fig. (1): Comparison between the two studied groups regarding age.

Comparison between the two studied groups regarding Sex

Table (2), show the Comparison between the two studied groups regarding Sex .Group one include 45 patient 7 were female with $15.6 \%$ \& 38 male with $84.4 \%$. Group two include 55 patient 10 were female with $18.2 \%$ \& 45 male with $81.8 \%$. There was no significant difference between the two group as regard Sex.

\begin{tabular}{|c|c|c|c|c|c|}
\hline & & & Group & & \\
\hline & & & RBG $<180$ & RBG > 180 & Total \\
\hline Sex & female & No. & 7 & 10 & 17 \\
\hline & & $\%$ & $15.6 \%$ & $18.2 \%$ & $17.0 \%$ \\
\hline & male & No. & 38 & 45 & 83 \\
\hline & & $\%$ & $84.4 \%$ & $81.8 \%$ & $83.0 \%$ \\
\hline Tota & & No. & 45 & 55 & 100 \\
\hline & & $\%$ & $100.0 \%$ & $100.0 \%$ & $100.0 \%$ \\
\hline $\begin{array}{l}\mathrm{X} 2 \\
\mathrm{p}\end{array}$ & & & $\begin{array}{l}.006 \\
.936\end{array}$ & & \\
\hline
\end{tabular}

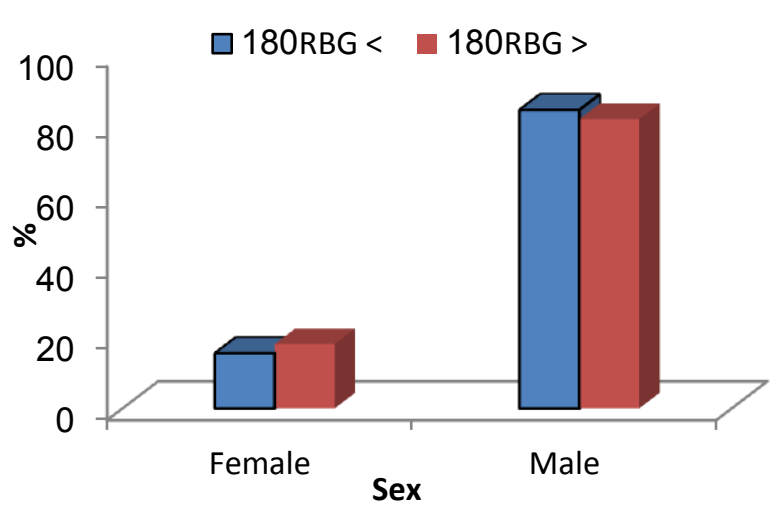

Fig. (2):Comparison between the two studied groups regarding Sex 
Comparison between the two studied groups regarding HbA1c

Table (3) Comparison between the two studied groups regarding $\mathrm{HbA} 1 \mathrm{c}$ where group one include 45 patient with mean $5.7400 \&$ SD 0.29879. Group two include 55 patient with mean $6.100 \&$ SD 0.6200 . There was no significant difference between the two groups as regard $\mathrm{HbA1c}$.

\begin{tabular}{|l|l|l|l|l|l|l|l|}
\hline HbA1c & $\mathbf{N}$ & Minimum & Maximum & Mean & S.D & t & p \\
\hline RBG $<180$ & 45 & 5.00 & 6.10 & 5.7400 & .29879 & & \multirow{2}{*}{0.098} \\
\cline { 1 - 6 }$>180$ & 55 & 5.40 & 9.00 & 6.100 & .6200 & 1.83 & NS \\
\hline Total & 100 & 5.00 & 9.00 & 6.5050 & .95509 & & \\
\hline
\end{tabular}

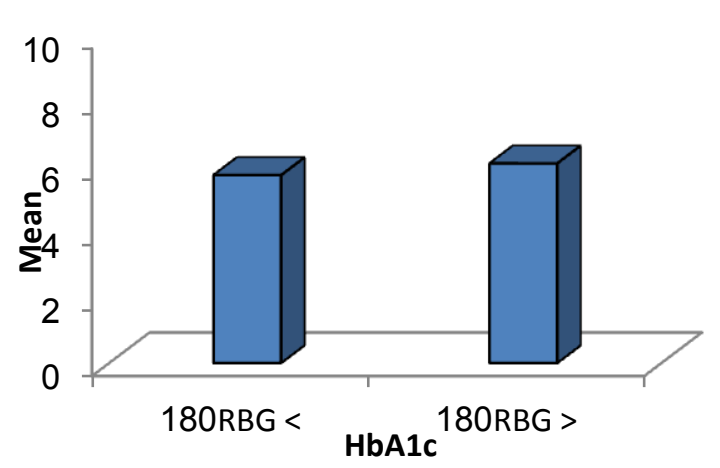

Fig. (3): Comparison between the two studied groups regarding HbA1c

\section{Comparison between the two studied groups regarding Lipid profile}

Table (4), show the comparison between the two studied groups regarding Lipid profile, T.G. level in Group one include 45 patient with mean 238.3111 \& SD 56.82542. Group two include 55 patient with mean 249, 5273 \& SD 61.33570. There was no significant between the two groups as regarde TG.

Cholesterol in group one include 45 patient with mean 248.9556 \& SD 62.817108. Group two include 55 patient with mean $266.6727 \&$ SD 67.77442. There was no significant difference between the two groups as regarde Cholesterol.

\begin{tabular}{|l|l|l|l|l|l|l|l|l|}
\hline \multicolumn{2}{|c|}{} & $\mathbf{N}$ & $\begin{array}{l}\text { Mini } \\
\text { mum }\end{array}$ & $\begin{array}{l}\text { Maxi } \\
\text { mum }\end{array}$ & Mean & S.D & t & p \\
\hline \multirow{4}{*}{ TG } & $\begin{array}{l}\text { RBG } \\
<180\end{array}$ & 45 & 157.00 & 347.00 & 238.3111 & 56.82542 & & \\
\cline { 2 - 7 } & $\begin{array}{l}\text { RBG } \\
>180\end{array}$ & 55 & 155.00 & 351.00 & 249.5273 & 61.33570 & .884 & .349 \\
\cline { 2 - 7 } & Total & 100 & 155.00 & 351.00 & 244.4800 & 59.31826 & & \\
\hline \multirow{5}{*}{ Cholesterol } & $\begin{array}{l}\text { RBG } \\
<180\end{array}$ & 45 & 149.00 & 357.00 & 248.9556 & 62.81718 & & \\
\cline { 2 - 7 } & $\begin{array}{l}\text { RBG } \\
>180\end{array}$ & 55 & 162.00 & 378.00 & 266.6727 & 67.77442 & 1.806 & .182 \\
\cline { 2 - 6 } & Total & 100 & 149.00 & 378.00 & 258.7000 & 65.86142 & & \\
\hline
\end{tabular}

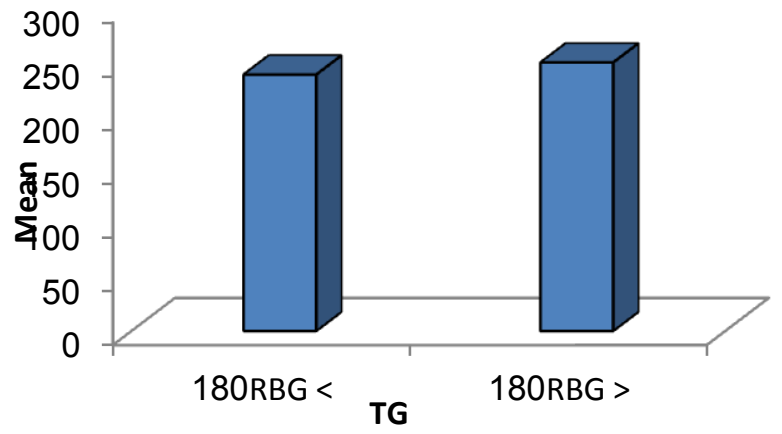

Fig. (4): Comparison between the two studied groups regarding $\mathrm{TG}$.

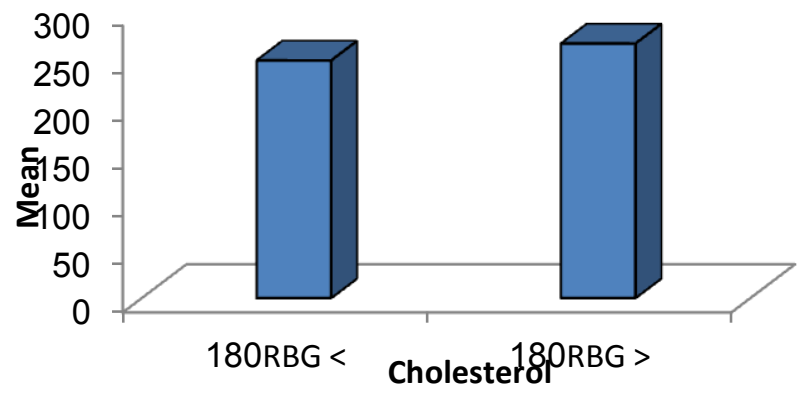

Fig. (5): Comparison between the two studied groups regarding cholestrerol.

\section{Comparison between the two studied groups regarding Treatment}

Table (5), show the comparison between the two studied groups regarding Treatment. Group one include 45 patient 26 did PCI with $57.8 \%$ \& 19 received thrombolytic with $42.2 \%$. Group two include 55 patient 32 did PCI with $58.2 \%$ \& 23 received thrombolytic with $41.8 \%$.

There was no significant difference between the two groups as regard type of treatment.

\begin{tabular}{|c|c|c|c|c|}
\hline \multirow{2}{*}{\multicolumn{2}{|c|}{ Treatment }} & \multicolumn{2}{|l|}{ Group } & \multirow{3}{*}{\begin{tabular}{|l} 
Total \\
58
\end{tabular}} \\
\hline & & \multirow{2}{*}{\begin{tabular}{|l} 
RBG $<\mathbf{1 8 0}$ \\
26
\end{tabular}} & \multirow{2}{*}{$\begin{array}{l}\text { RBG } \\
>\mathbf{1 8 0} \\
32\end{array}$} & \\
\hline \multirow[t]{2}{*}{ pci } & No. & & & \\
\hline & $\%$ & $57.8 \%$ & $58.2 \%$ & $58.0 \%$ \\
\hline \multirow[t]{2}{*}{ thrombolytic } & No. & 19 & 23 & 42 \\
\hline & $\%$ & $42.2 \%$ & $41.8 \%$ & $42.0 \%$ \\
\hline \multirow[t]{2}{*}{ Total } & No. & 45 & 55 & 100 \\
\hline & $\%$ & $100.0 \%$ & $100.0 \%$ & $100.0 \%$ \\
\hline $\begin{array}{l}\mathrm{X}^{2} \\
\mathrm{P}\end{array}$ & & \multicolumn{2}{|l|}{.012} & \\
\hline
\end{tabular}




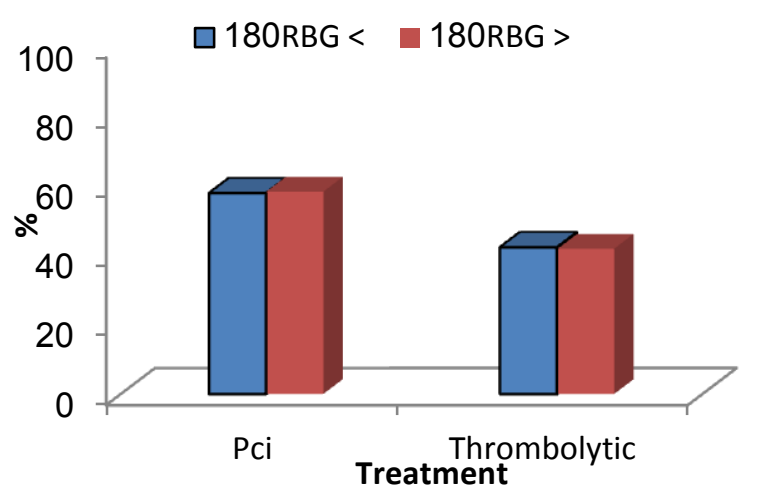

Fig.(6): Comparison between the two studied groups regarding Treatment

Comparison between the two studied groups regarding blood Glucose level after 3 months

Table (6), show the comparison between the two studied groups regarding Glucose level after 3 months. Group one include 45 patient with mean 103.5333 \& SD 24.00530. Group two include 55 patient with mean 177.7636 \& SD 41.32660 .

There was significant correlation between the two groups as regarde blood glucose level after 3 month.

\begin{tabular}{|l|l|l|l|l|l|l|l|}
\hline $\begin{array}{l}\text { Glucose } \\
\text { level }\end{array}$ & $\mathbf{N}$ & $\begin{array}{l}\text { Mini } \\
\text { mum }\end{array}$ & $\begin{array}{l}\text { Maxi } \\
\text { mum }\end{array}$ & Mean & S.D & T & p \\
\cline { 1 - 5 } $\begin{array}{l}\text { RBG } \\
<180\end{array}$ & 45 & 80.00 & 145.00 & 103.5333 & 24.00530 & & \\
\cline { 1 - 1 } $\begin{array}{l}\text { RBG } \\
>180\end{array}$ & 55 & 95.00 & 322.00 & 177.7636 & 41.32660 & 113.665 & $.0001^{*}$ \\
\cline { 1 - 5 } Total & 100 & 80.00 & 322.00 & 144.3600 & 50.64803 & & \\
\hline
\end{tabular}

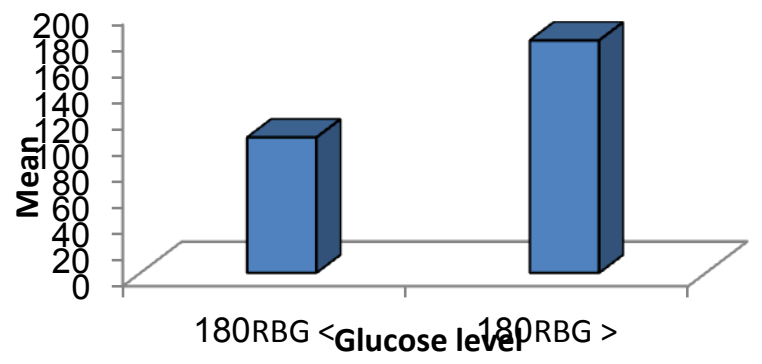

Fig.(7):Comparison between the two studied groups regarding blood Glucose level after 3 months.

Comparison between the two studied groups regarding mortality

Table (7), show the comparison between the two studied groups regarding mortality. Group one include 45 patient where 2 patient die with a percentage $4.4 \%$ and group two include 55 patient where 6 patient die with a percentage $10.9 \%$.there is no significant correlation between the two groups.

\begin{tabular}{|l|l|l|l|l|}
\hline \multirow{2}{*}{} & \multicolumn{2}{|l|}{$\begin{array}{l}\text { Gp. I } \\
\text { RBG }<\mathbf{1 8 0}\end{array}$} & \multicolumn{2}{l|}{$\begin{array}{l}\text { Gp. II } \\
\text { RBG }>\mathbf{1 8 0}\end{array}$} \\
\cline { 2 - 5 } & No. & $\%$ & No. & $\%$ \\
\hline Die & 2 & 4.4 & 6 & 10.9 \\
\hline Survive & 43 & 95.6 & 49 & 89.1 \\
\hline Total & 45 & 100.0 & 55 & 100.0 \\
\hline$X^{2}$ & 1.41 & \multicolumn{2}{|l}{} \\
p & 0.235 & \multicolumn{2}{|l}{} \\
\hline
\end{tabular}

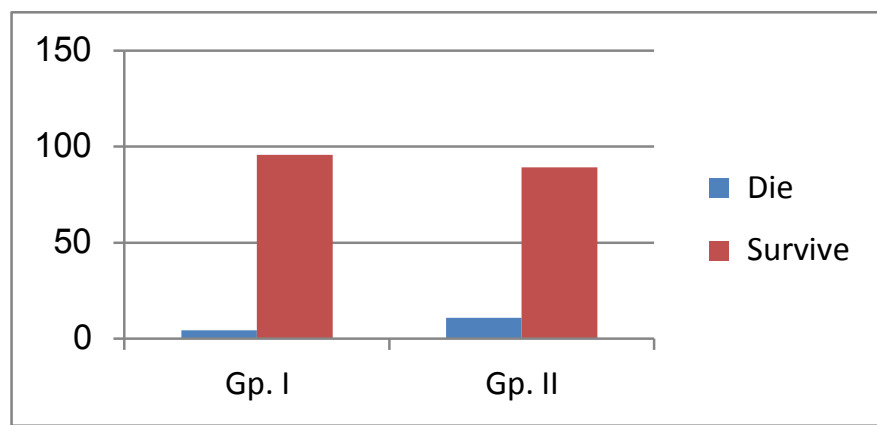

Fig. (8): Comparison between the two studied groups regarding mortality.

Comparison between the two studied groups regarding Prognosis cardiac during hospital stay

Table (8), show the comparison between the two studied groups regarding Prognosis cardiac during hospital stay.Group one include 45 patient where 2 patient experience heart failure with $4.4 \%, 3$ patient with arrthymia with $6.7 \%$ and 3 patient with cardiogenic shock with $6.7 \%$.Group two include 55 patient where 5 paient with heart failure with $9.1 \%, 2$ patient with ReMI with 3.6\% ,6 patient with arrthymia with $10.9 \%$ and 10 patient with cardiogenic shock with $18.2 \%$.there is significant correlation between the two groups.

\begin{tabular}{|l|l|l|l|l|}
\hline \multirow{2}{*}{} & \multicolumn{2}{|l|}{$\begin{array}{l}\text { Gp. I } \\
\text { RBG }<\mathbf{1 8 0}\end{array}$} & \multicolumn{2}{l|}{$\begin{array}{l}\text { Gp. II } \\
\text { RBG }>\mathbf{1 8 0}\end{array}$} \\
\cline { 2 - 5 } & No. & \% & No. & \% \\
\hline Heart failure & 2 & 4.4 & 5 & 9.1 \\
\hline ReMI & 0 & 0.0 & 2 & 3.6 \\
\hline Arrthymia & 3 & 6.7 & 6 & 10.9 \\
\hline Cardiogenic shock & 3 & 6.7 & 10 & 18.2 \\
\hline$X^{2}$ & 2.65 & \multicolumn{3}{|l}{} \\
p & 0.0107 & \multicolumn{3}{|l}{} \\
\hline
\end{tabular}




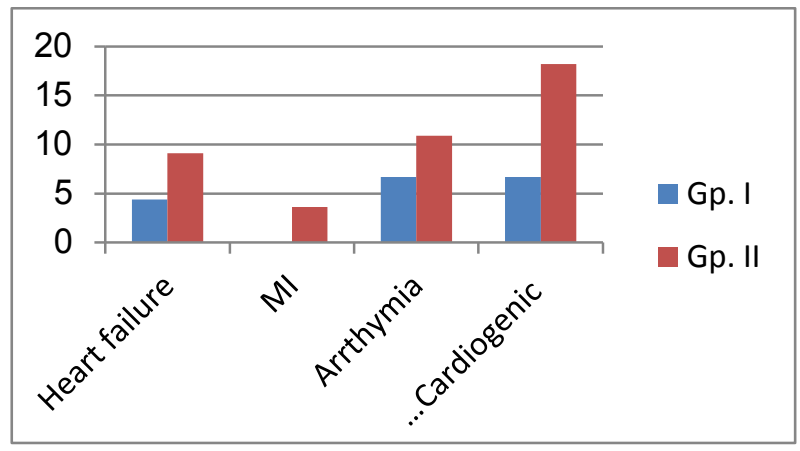

Fig.(9):Comparison between the two studied groups regarding Prognosis cardiac during hospital stay.

Comparison between the two studied groups regarding Prognosis cardiac after three months

Table (9), show the comparison between the two studied groups regarding Prognosis cardiac. Goup one include 45 patient 20 were free from complications with $44.4 \% \& 5$ with heart failure with $11.1 \%$ \& 10 with MI with $22.2 \%$ \& 7 with arrthymia with $15.6 \%$ \& 3 with cardiogenic shock with $6.7 \%$. Group two include 55 patient 10 were free from complications with $18.2 \%$ \& 10 with heart failure with $18.2 \%$ \& 15 with MI with $27.2 \%$ \& 10 with arrthymia with $18.2 \%$ \& 10 with cardiogenic shoch with $18.2 \%$. There was significant correlation between the two groups.

\begin{tabular}{|c|c|c|c|c|}
\hline \multirow{2}{*}{\multicolumn{2}{|c|}{ Prognosis cardiac }} & \multicolumn{2}{|l|}{ Group } & \multirow[b]{2}{*}{ Total } \\
\hline & & \multirow{2}{*}{\begin{tabular}{|l|} 
RBG \\
$<\mathbf{1 8 0}$ \\
20 \\
\end{tabular}} & \multirow{2}{*}{ 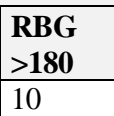 } & \\
\hline Free & No. & & & 30 \\
\hline & $\%$ & 44.4 & 18.2 & 30.0 \\
\hline \multirow{2}{*}{ Heart failure } & No. & 5 & 10 & 15 \\
\hline & $\%$ & 11.1 & 18.2 & 15.0 \\
\hline \multirow[t]{2}{*}{ ReMI } & No. & 10 & 15 & 25 \\
\hline & $\%$ & 22.2 & 27.2 & 25.0 \\
\hline \multirow[t]{2}{*}{\begin{tabular}{|l|} 
Arrthymia \\
\end{tabular}} & No. & 7 & 10 & 17 \\
\hline & $\%$ & 15.6 & 18.2 & 17.0 \\
\hline \multirow[t]{2}{*}{ Cardiogenic shock } & No. & 3 & 10 & 13 \\
\hline & $\%$ & 6.7 & 18.2 & 13.0 \\
\hline \multirow[t]{2}{*}{ Total } & No. & 45 & 55 & 100 \\
\hline & $\%$ & $100.0 \%$ & $100.0 \%$ & $100.0 \%$ \\
\hline $\begin{array}{l}\mathrm{X}^{2} \\
\mathrm{P}\end{array}$ & & \multicolumn{2}{|l|}{$\begin{array}{l}60.6 \\
.0001 *\end{array}$} & \\
\hline
\end{tabular}

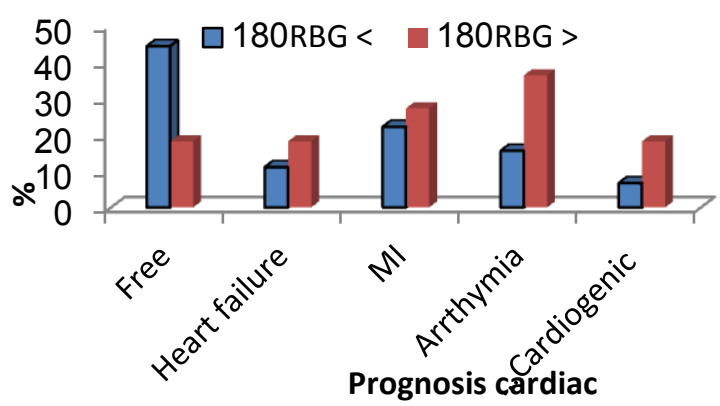

Fig. (10): Comparison between the two studied groups regarding Prognosis cardiac after three months

Comparison between the two studied groups regarding Prognosis DM after three months

Table (10), show the comparison between the two studied groups regarding Prognosis DM. Group one include 45 patient 2 were diabetic with $4.4 \% \& 43$ were free with $95.6 \%$. Group two include 55 patient 28 were diabetic with $55 \%$ \& 27 were free with $49 \%$. There was significant correlation between the two groups.

\begin{tabular}{|l|l|l|l|l|}
\hline \multirow{2}{*}{ Prognosis DM } & \multicolumn{2}{|l|}{ Group } & \multirow{2}{*}{ Total } \\
\cline { 3 - 5 } \cline { 3 - 5 } & RBG <180 & RBG >180 & Th \\
\cline { 2 - 5 } & No. & 2 & 28 & 30 \\
\hline \multirow{2}{*}{ negative } & No. & $4.4 \%$ & 55.00 & 30 \\
\cline { 2 - 5 } & $\%$ & 43 & 27 & 70 \\
\hline Total & No. & $95.6 \%$ & 49.00 & 70 \\
\cline { 2 - 5 } & $\%$ & 45 & 55 & 100 \\
\hline $\mathrm{X}^{2}$ & & $100.0 \%$ & $100.0 \%$ & $100.0 \%$ \\
$\mathrm{P}$ & & 11.92 & \\
\hline
\end{tabular}

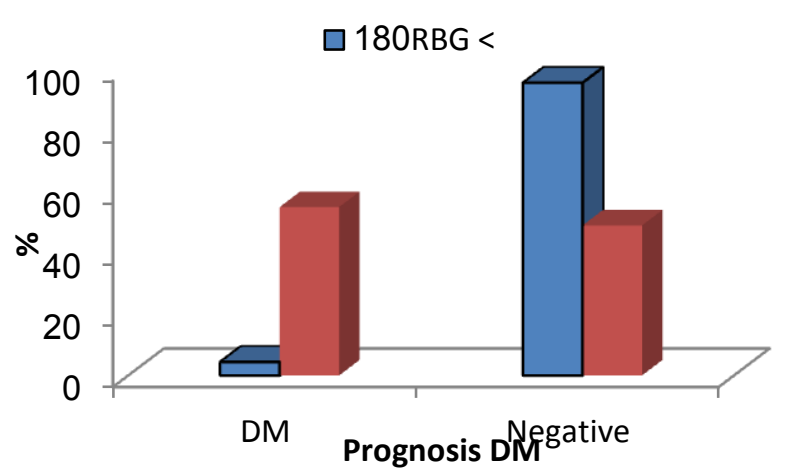

Fig. (11): Comparison between the two studied groups regarding Prognosis DM after three months 
Correlation between HbA1c and glucose level on admission and glucose after 3 months

Table (22): show the correlation between HbAlc and glucose level on admission and glucose after 3 months, it was found that there was a positive significant correlation between HbAlc and glucose level after 3 months, while there was no significant relation between $\mathrm{HbAlc}$ and glucose level on admission.

\begin{tabular}{|l|l|l|}
\hline HbA1c & R & P \\
\hline Glucose level on admission & 0.231 & 0.108 \\
\hline Glucose level after 3 months & 0.742 & $0.001^{*}$ \\
\hline
\end{tabular}

\section{DISCUSSION}

Diabetes mellitus is an established major cardiovascular risk factor associated with increased prevalence of coronary artery disease $(\mathrm{CAD})^{(4)}$. Patients with diabetes often have numerous concomitant cardiac risk factors with a higher incidence of AMI and CHF. Poor glycemic control and insulin resistance are associated with significant endothelial cell dysfunction, procoagulability, and diffuse multivessel CAD.

A high blood glucose level on admission is often attributed to 'stress hyperglycemia' and might reflect an acute response to the hyperadrenergic state. The impact of admission blood glucose level, as an indicator of glucometabolic state, has been less well studied in the setting of acute coronary syndromes but appears to be a marker of adverse outcome after STEMI ${ }^{(5,6)}$.

Interventional studies have established that cardiovascular complications are mainly or partly dependent on sustained chronic hyperglycemia ${ }^{(7,8)}$. This glycemic disorder can be estimated as a whole from the determination of HbAlc level, which integrates both basal and postprandial hyperglycemia $(9,10)$

HbAlc reflects the average blood glucose concentrations over the preceding 2-3 months. There are advantages of HbAlc testing compared with plasma glucose. The measurement of HbAlc is well standardized, and the biologic variability is less and does not require fasting. In addition, it is relatively unaffected by acute changes in glucose levels.

Hence, we aimed in this study to assess the impact of admission blood glucose level and HbAlc on the hospital course and outcome in patients presenting with STEMI in ICU.

In our study, we included 100 patients with STEMI, 83 patients were men and 17 were women, divided into two groups: group I included 45 patients with admission blood glucose level less than $180 \mathrm{mg} / \mathrm{dl}$ and group II included 55 patients with admission blood glucose level $180 \mathrm{mg} / \mathrm{dl}$ or more (the level 180 was chosen according to the NICE-SHUGAR study investigators) ${ }^{(11)}$.

All patients were subjected to complete history taking and complete clinical examination; 12-lead ECG was performed for every patients and routine laboratory investigations were performed, including cardiac enzymes, which were important for diagnosis of AMI. Admission blood glucose level and $\mathrm{HbAlc}$ were estimated at the time of admission of the patients.

Our study substantially expands the current understanding of the relationship between admission glucose values and adverse outcomes in patients with STEMI

We tried to find this correlation between GOA and $\mathrm{HbAlc}$ with the adverse outcome of these patients who were admitted to the critical care unit with AMI.

With respect to age and sex, there was no significant correlation with elevated GOA or HbA1 in these patients; this is in agreement with the study conducted by Cakmak et al. ${ }^{(12)}$, who studied 100 patients with elevated GOA and HbA1c and could not detect any significant correlation between sex and clinical results.

There was a significant correlation between history of both smoking and diabetes mellitus and elevated GOA. and these results are in agreement with the results of Pres et al. ${ }^{(13)}$ who also detected the highest significant correlation between history of both smoking and diabetes mellitus and elevated GOA.

In contrast, there was no significant correlation between history of hypercholesterolemia or hypertension among our study.

We detected an increased incidence of developing 
heart failure (detected by low ejection fraction) in patients with AMI and elevated GOA level, with high significant correlation between them. These results are in agreement with the study by Gasior et al. (14) in which of the 3166 consecutive patients with STEMI 258 had heart failure.

In agreement with our study, Kosiborod and McGuire $^{(15)}$ also found that higher blood GOA in patients with AMI was associated with higher Killip classification and lower ejection fraction \%.

We could not assess the proper correlation between elevated GOA or HbA1c and mortality as only two patient from group I died and 6 patients from group II died.

This is not in agreement with the study by Kosiborod and McGuire ${ }^{(15)}$, who studied 141680 patients hospitalized with AMI over 2-year study duration; they concluded that higher glucose levels were associated with greater 30-day mortality.

The difference between our results and the results of these studies may be because of difference in sample size as their studies were conducted on a very high number of patients.

With respect to $\mathrm{HbA1c}$, we did not find any significant correlation between its level and outcome of patients with AMI, and this is in agreement with the study conducted by Timmer ${ }^{(16)}$ who concluded that elevated $\mathrm{HbA} 1 \mathrm{c}$ was not significantly associated with increased mortality or adverse outcome in their study, which was previously described.

Similarly, study by Chan et $a l^{(17)}$ suggested that HbA1c level before admission is not associated with short-term cardiovascular outcome in diabetic patients subsequently admitted with acute coronary syndrome. In contrast to our study was a systematic review by Liu et al. ${ }^{(18)}$ to quantify the association between elevated HbA1c level and all-cause mortality among patients hospitalized with CAD. A systematic search of electronic databases for studies published from 1970 to May 2011 was performed. Cohort, case-control studies, and randomized controlled trials that examined the effect of HbA1c on all-cause mortality in patients with acute coronary syndrome were included.

Finally, our discussion concluded that elevated admission blood glucose level in patients with AMI appears more important than prior long-term abnormal glucose metabolism (detected by elevated $\mathrm{HbA1c}$ ) in predicting outcome in patients with AMI, and this may be because a stress response accompanied by high levels of catecholamines and cortisol; these hormones increase glycogenolysis and lipolysis and reduce insulin sensitivity, resulting in elevated glucose levels ${ }^{(12)}$.

Therefore, patients with elevated glucose levels may represent patients with an increased stress response, for example, due to more severe hemodynamic compromise or more extensive myocardial damage $^{(19,20)}$. Stress hyperglycemia increases mortality, CHF, and cardiogenic shock after AMI ${ }^{(21)}$. Elevated cytokine, particularly tumor necrosis factora (TNF-a), also increases glucose levels. TNF-a is released in AMI and directly decreases myocardial contractility, probably by inducing myocardial apoptosis $^{(22)}$.TNF-a also causes impaired endothelial function ${ }^{(23)}$. This, in turn, may be responsible for impaired myocardial perfusion.

\section{REFERENCES}

1. Capes SE, Hunt D, Malmberg K, Gerstein HC. Stress hyperglycaemia and increased risk of death after myocardial infarction in patients with and without diabetes. a systematic overview. Lancet 2000; 356:773778.

2. Norhammer AM, Ryden L, Malmberg K. Admission plasma glucose. Independent risk factor for long-term prognosis after myocardial infarction even in nondiabetic patients. Diabetes Care 1999; 22:1827-1831.

3. Sewardsen M, Vythilingum S, Jialal I, Becker PJ. Prognostic importance of admission plasma glucose in diabetic and non-diabetic patients with acute myocardial infarction. Q J Med 1989; 265:461-466.

4. Hammoud T, Tanguay JF, Bourassa MG. Management of coronary artery disease. Therapeutic options in patients with diabetes. J Am Coll Cardiol 2000; 36:355- 
365.

5. Bartnik $M$, Malmberg $K$, Norhammar $A$, Tenerz A, Ohrvik J, Ryde'n L. Newly detected abnormal glucose tolerance: an important predictor of long-term outcome after myocardial infarction. Eur Heart J 2004; 25:1990-1997.

6. Zeller M, Cottin Y, Brindisi MC. RICO Survey Working Group. Impaired fasting glucose and cardiogenic shock in patients with acute myocardial infarction. Eur Heart J 2004; 25:308312.

7. The Diabetes Control and Complications Trial Research Group. The effect of intensive treatment of diabetes on the development and progression of longterm complications in insulindependent diabetes mellitus. N Engl J Med 1993; 329:977986.

8. Adler AI, Stratton IM, Neil HA, Yudkin JS, Matthews DR, Cull CA, et al. Association of systolic blood pressure with macrovascular and microvascular complications of type 2 diabetes (UKPDS 36): prospective observational study. BMJ 2000; 321:412.

9. Sacks DB, Bruns DE, Goldstein DE, Maclaren NK, McDonald JM, Parrott M. Guidelines and recommendations for laboratory analysis in the diagnosis and management of diabetes mellitus. Clin Chem 2002; 48:436-472.

10. Gorus F, Mathieu C, Gerlo E. How should $\mathrm{HbA1c}$ measurements be reported? Diabetologia 2006; 49:7-10.

11. The NICE-SUGAR Study Investigators. Intensive versus conventional glucose control in critically ill patients. N Engl J Med 2009; 360:1283- 1297.

12. M Cakmak, N Cakmak, S Cetemen, H Tanriverdi, Y Enc, O Teskin, ID Kilic. The value of admission glycosylated hemoglobin level in patients with acute myocardial infarction. Can J Cardiol 2008; 24:375-378.

13. Pres D, Gasior M, Lekston A, Gierlotka M, Hawranek M, Tajstra M, Buchta P, et al. Relationship between low-density lipoprotein cholesterol level on admission and in-hospital mortality in patients with ST-segment elevation myocardial infarction, with or without diabetes, treated with percutaneous coronary intervention. Kardiol Pol 2010; 68:1005-1012.

14. Gasior M, Stasik-Pres G, Pres D, Lech P, Gierlotka M, Lekston A, et al. Relationship between blood glucose on admission and prognosis in patients with acute myocardial infarction treated with percutaneous coronary intervention. Kardiol Pol 2007; 65:1031-1038. discussion 1039-1040

15. M Kosiborod, DK McGuire. Glycated hemoglobin as a prognostic risk marker in nondiabetic patients after acute myocardial infarction. Circulation 2011; 124:666-668.

16. Jorik Rudolf Timmer, Clinical implications of glycometabolic disturbances in acute coronary syndromes / Jorik Rudolf Timmer.(S.1.:s.n.), 2005 (Ensch ede):Febodruk).- 203 p.: ill.; 24 $\mathrm{cm}$.

17. CY Chan, R Li, JY Chan, et al. The value of Admission HbA1c level in diabetic patients with acute coronary syndrome. Clin Cardiol 2011; 34:507-512.

18. Y Liu, Y-M Yang, J Zhu, H-Q Tan, Y Liang, JD Li. Prognostic significance of hemoglobin A1c level in patients hospitalized with coronary artery disease. A systematic review and meta-analysis. Cardiovasc Diabetol 2011; 10:98.

19. DeGeare VS, Boura JA, Grines LL, O’Neill WW, Grines CL. Predictive value of the Killip classification in patients undergoing primary percutaneous coronary intervention for acute myocardial infarction. Am J Cardiol 2001;87:1035-1038.

20. Gosselink AT, Liem AL, Reiffers S, Zijlstra F Prognostic value of predischarge radionuclide ventriculography at rest and exercise after acute myocardial infarction treated with thrombolytic therapy or primary coronary angioplasty. The Zwolle Myocardial Infarction Study Group. Clin Cardiol 1998; 21:254-260. 
21. Levetan CS, Passaro M, Jablonski K, Kass M, Ratner RE. Unrecognized diabetes among hospitalized patients. Diabetes Care 1998; 21:246-249.

22. Li D, Zhao L, Liu M, et al. Kinetics of tumor necrosis factor alpha in plasma and the cardioprotective effect of a monoclonal antibody to tumor necrosis factor alpha in acute myocardial infarction. Am Heart J 1999; 137:1145- 1152.

23. Fujita H, Morita I, Murota S. A possible involvement of ion transporter in tumor necrosis factor alpha and cycloheximide-induced apoptosis of endothelial cells. Mediators Inflamm 1999; 8:211218. 